\title{
Practical approach to detection and management of acute kidney injury in critically ill patient
}

\author{
Vahid Mohsenin ${ }^{1,2}$ (D)
}

\begin{abstract}
Background: Acute kidney injury (AKI) is a common complication in critically ill patients and is associated with high morbidity and mortality. This paper provides a critical review of the etiologies of AKI and a systematic approach toward its diagnosis and management with emphasis on fluid volume assessment and the use of urine biochemical profile and microscopy in identifying the nature and the site of kidney injury.

Materials and methods: The search of PubMed and selection of papers had employed observational designs or randomized control trials relevant to AKI.

Results: AKI is defined by the rate of rise of serum creatinine and a decline in urine output. The pathophysiology is diverse and requires a careful and systematic assessment of predisposing factors and localization of site of injury. The majority of AKls are due to prerenal causes such as fluid volume deficit, sepsis, or renal as in acute tubular injury. The use of central venous and arterial blood pressure monitoring and inferior vena cava echocardiography complemented by urine analysis and microscopy allows assessment of fluid volume status and AKl etiology.
\end{abstract}

Conclusions: Timely intervention by avoidance of fluid volume deficit and nephrotoxic agents and blood pressure support can reduce the incidence of AKI in critically ill patients.

Keywords: Acute kidney injury, Fluid volume assessment, Urine microscopy, Critical illness

\section{Background}

Acute kidney injury (AKI) is a common complication among patients with critical illness in the intensive care unit (ICU). The incidence of AKI is now believed to be significantly higher than previously believed with over $50 \%$ of patients in the ICU developing AKI at some point during the course of their critical illness. Mortality among ICU patients with AKI and multi-organ failure has been reported to be more than 50\% [1-3]. Those that require renal replacement therapy (RRT) mortality may be as high as $80 \%$ [4-6]. AKI is characterized by a sudden decrease in kidney function over a period of hours to days, resulting in accumulation of creatinine, urea, and other waste products. A consensus definition of AKI and formulation of the RIFLE criteria-acronym RIFLE stands for Risk,

\footnotetext{
Correspondence: Vahid.mohsenin@yale.edu

${ }^{1}$ Section of Pulmonary, Critical Care and Sleep Medicine, Yale School of Medicine, New Haven, CT, USA

${ }^{2}$ Department of Medicine, Lippard Laboratory of Clinical Investigation, Yale School of Medicine, 15 York Street, LLCl-106-E, New Haven, CT 06510, USA
}

Injury, and Failure; and the two outcome classes, Loss and End-Stage Renal Disease [7, 8]-is based on the degree of rise of serum creatinine, decreased in glomerular filtration rate (GFR), and urine output. The most recent definition of AKI represents a harmonization of the previous RIFLE and Acute Kidney Injury Network (AKIN) [8] classifications with increased sensitivity for diagnosis of AKI. According to the 2012 Kidney Disease: Improving Global Outcomes (KDIGO) consensus guidelines, AKI is defined by an increase in the serum creatinine level of $0.3 \mathrm{mg} / \mathrm{dL}$ $(26.5 \mu \mathrm{mol} / \mathrm{L})$ or more within $48 \mathrm{~h}$; a serum creatinine level that has increased by at least 1.5 times the baseline value within the previous 7 days; or a urine volume of less than $0.5 \mathrm{~mL}$ per kilogram of body weight per hour for $6 \mathrm{~h}$. For AKI staging purposes, patients should be staged according to the criteria that give them the highest stage (Table 1) [9]. However, this definition does not offer any understanding of pathophysiological mechanism underlying AKI; it can be thought of more like acute lung injury. 
Table 1 Definition and staging of acute kidney injury: KDIGO criteria

\begin{tabular}{lll}
\hline Stage & Serum creatinine & Urine output \\
\hline 1 & $1.5-1.9$ times baseline & $<0.5 \mathrm{~mL} / \mathrm{kg} / \mathrm{h} \mathrm{for} 6-12 \mathrm{~h}$ \\
& OR & \\
& $\geq 0.3 \mathrm{mg} / \mathrm{dL}(\geq 26.5 \mu \mathrm{mol} / \mathrm{L})$ increase & $<0.5 \mathrm{~mL} / \mathrm{kg} / \mathrm{h} \mathrm{for} \geq 12 \mathrm{~h}$ \\
2 & $2.0-2.9$ times baseline & $<0.3 \mathrm{~mL} / \mathrm{kg} / \mathrm{min} \mathrm{for} \geq 24 \mathrm{~h}$ \\
3 & 3.0 times baseline & OR \\
& OR & Anuria $\geq 12 \mathrm{~h}$ \\
& Increase in serum creatinine to $\geq 4.0 \mathrm{mg} / \mathrm{dL}(\geq 353.6 \mu \mathrm{mol} / \mathrm{L})$ & \\
& OR & \\
& Initiation of renal replacement therapy $\mathrm{OR}$, in patients $<18$ years, & \\
& decrease in eGFR to $<35 \mathrm{~mL} / \mathrm{min}$ per $1.73 \mathrm{~m}^{2}$ & \\
&
\end{tabular}

AKI is the consensus term for acute renal failure [10]. The term AKI meant to imply that an injury process existed before any loss of kidney function can be measured with standard laboratory tests. The main criterion used to define AKI is the rate of rise of serum creatinine. However, the degree of renal dysfunction can be underestimated due to changes in the volume of distribution, falls in creatinine generation in patients with advanced chronic kidney disease (CKD) [11], and loss of muscle mass in critically ill patients $[12,13]$.

The time-honored classification of AKI to prerenal azotemia, intrinsic renal diseases, and post-renal urinary obstruction provides a conceptual framework by which pathophysiological mechanisms can be investigated [14]. The current evidence supports the validity of KDIGO criteria to identify groups of hospitalized patients with increased risk of death and/or need for RRT. There is accumulating evidence of long-term risk of subsequent development of cardiovascular disease or CKD, even after apparent resolution of AKI [15-17].

\section{Causes of AKI}

The pathogenesis of AKI is complex due to multiple etiologies and risk factors (Table 2). Risk factors include increasing age, presence of heart failure, liver failure, CKD, anemia, and exposures to nephrotoxic agents including antibiotics, non-steroidal anti-inflammatory drugs (NSAIDS), and radiocontrast dyes. Infections, sepsis, shock, need for mechanical ventilation, and surgery are well recognized as high-risk settings for the development of AKI [18]. AKI is a broad clinical syndrome encompassing various etiologies, including specific kidney diseases (e.g., acute tubular necrosis, acute interstitial nephritis, acute glomerular, and vasculitis renal diseases), non-specific conditions (e.g., ischemia, toxic injury), and extrarenal pathology (e.g., prerenal azotemia and acute post-renal obstructive nephropathy).

Prerenal AKI including sepsis accounts for $60-70 \%$ of all AKI cases in critically ill patients [1]. Renal blood flow (RBF) autoregulation through its synchronized interplay of afferent and efferent arterioles maintains a constant RBF and GFR within a wide range of mean arterial blood pressure (80-180 $\mathrm{mmHg}$ ) [19]. A decline in the GFR reflects a reduction in blood pressure below the lower limit of the autoregulatory range. However, a significant decline in blood pressure must occur to induce a sufficient reduction in GFR with subsequent development of AKI. In the tubuloglomerular feedback (TGF) mechanism through macula densa, when blood pressure decreases, the vasodilators (vasodilator prostaglandins and nitric oxide) are released with afferent arteriolar vasodilation and subsequent stimulation of renin-angiotensin-aldosterone system (RAAS) [20, 21]. The opposite occurs when blood pressure increases with generation of vasoconstrictor mediators (vasoconstrictor ATP and adenosine), causing afferent arteriolar vasoconstriction while the efferent arteriole dilates to stabilize RBF and GFR. The TGF mechanism and the myogenic activity of the afferent arteriole provide an estimated

Table 2 Etiologies of AKI

Prerenal AK

- Dehydration (vomiting, diarrhea)

- Bleeding or hypovolemia

- Heart failure

- Liver failure

- Narrowing of renal arteries

- Renal microangiopathy

- Exposure to vasoactive drugs

Renal AKI

- Acute tubular injury/toxicity

- Drugs (common in ICU)

- Aminoglycosides, vancomycin

- Amphotericin B, pentamidine

- Contrast dyes

- Bisphosphonates

- Cisplatin, ifosfamide, methotrexate (crystal nephropathy)

- Tumor lysis syndrome

- Multiple myeloma

- Rhabdomyolysis (crush injury, cocaine, heroin, ketamine, methadone, and methamphetamine)

- Tissue hypoperfusion, sepsis

- Acute interstitial nephritis

- Vancomycin, quinolones, rifampin, sulfonamides, $\beta$-lactams (penicillin, cephalosporins), acyclovir (crystal nephropathy)

- NSAIDs

- Ifosfamide, carboplatin, Adriamycin, tyrosine kinase inhibitor

Post-renal AKI reflects the obstruction of the urinary system, particularly the ureters. 
$90 \%$ of the autoregulation capacity of RBF [22]. Arterial blood pressure alone cannot sustain GFR, so these important autoregulatory mechanisms involving the TGFand RAAS-mediated compensations are needed. Risk of AKI increases when these mechanisms are inhibited through angiotensin converting enzyme inhibitors (ACEI) and NSAID [23, 24].

Sepsis and septic shock remain the most important causes of AKI in critically ill patients and account for more than $50 \%$ of cases of AKI in the ICU [3]. The common assumption has been that tissue hypoperfusion and renal ischemia are the mechanisms of AKI in sepsis and hyperdynamic septic shock. An increasing body of evidence suggests that in a significant proportion of patients, AKI can occur in the absence of overt signs of tissue hypoperfusion, suggesting that other mechanisms may be at work. Studies in animal models of sepsis [25, 26] and humans with sepsis and AKI $[27,28]$ have shown that as part of the systemic vasodilation observed during severe sepsis/septic shock, RBF is not decreased and even increased indicating that AKI occurs not in the setting of renal hypoperfusion. Furthermore, in septic animals and in postmortem observations in humans with sepsis-induced AKI, kidney histology is strikingly bland with focal areas of tubular injury, but minimal cell death $[29,30]$. In aggregate, these observations suggest the presence of three distinct perturbations as mechanisms of AKI in sepsis: diffuse microcirculatory flow abnormalities, inflammation, and cellular bioenergetic responses to injury [31, 32].

Renal AKI develops when the primary cause of AKI is parenchymal injury, caused by drugs, toxins, and ischemia. The mechanisms underlying the renal injury process in AKI have predominantly been studied in animal models of ischemic AKI, characterized by "activation" of epithelial and possibly endothelial cells during the early initiation phase results in the upregulation of a variety of chemokines and cytokines leading up to inflammatory cell infiltration including macrophages with loss of the brush border in the proximal tubular epithelium [33]. Nephrotoxic agents have been implicated as etiologic factors in $17-26 \%$ of in-hospital AKI [3, 34]. Patient's specific risk factors for drug nephrotoxicity are older age, female sex, hyperbilirubinemia, fluid volume depletion, and hypoalbuminemia by inducing toxic drug levels and increasing the unbound drug fraction in the serum. ACEI and angiotensin II receptor blockers could precipitate or potentiate AKI in certain situations. These include (1) bilateral renal artery stenosis or renal artery stenosis in solitary kidney, (2) volume depletion, and (3) concomitant use of NSAIDs, cyclosporine, and tacrolimus [35].

\section{Diagnosis}

AKI is diagnosed when serum creatinine increases by $\geq$ $0.3 \mathrm{mg} / \mathrm{dL}(\geq 26.5 \mu \mathrm{mol} / \mathrm{L})$ within $48 \mathrm{~h}$ or increase in serum creatinine to $\geq 1.5$ times baseline within the previous 7 days or urine volume $<0.5 \mathrm{~mL} / \mathrm{kg} / \mathrm{h}$ for $6 \mathrm{~h}$ [9].

\section{Fluid volume assessment}

The real challenge is to determine the cause of AKI. The first order is to assess the fluid volume status of the patient. This can be accomplished by estimating the fluid volume balance in the preceding days, blood pressure trend, and assessment of intravascular volume. Intravascular volume is not measured directly but can be inferred by the presence or absence of fluid responsiveness. Echocardiography examining the inferior vena cava diameter and its respiratory variation is becoming readily available in ICUs. More than $12 \%$ variation in the IVC diameter in mechanically ventilated patient with septic shock had greater than $90 \%$ positive predictive value (PPV) for fluid responsiveness implying intravascular volume deficit [36]. Central venous pressure (CVP) dynamic changes or arterial pulse pressure variation during respiratory cycle can also provide information about intravascular volume deficit [37]. A drop of $\geq 1 \mathrm{mmHg}$ in CVP during spontaneous inspiration or mechanical breath had a PPV of $84 \%$ and negative predictive value of $94 \%$ for fluid responsiveness in a mixed medical and surgical ICU [38]. In arterial pulse pressure variation of $>13 \%$ during respiratory cycle, the respective values were $94 \%$ and $96 \%$ [39].

\section{Urinary and serum biochemical measurements}

Urinary diagnostic indices can have confirmatory value (Table 3). Concentrated urine with urine-specific gravity $>1.020, \mathrm{BUN} / \mathrm{Cr}>20: 1$, urine $\mathrm{Na}<20 \mathrm{mEq} / \mathrm{L}$, or low FeNa $<1.0 \%$ are consistent with fluid volume deficit or renal hypoperfusion denoting a prerenal AKI. On the other hand, rising serum creatinine with $\mathrm{FeNa}>2.0 \%$ highly suggests renal AKI. However, some caveats should be noted with these measures as outlined in Table 3. Studies on biochemical analysis of urine using standard measurements of sodium, urea, and creatinine and calculating various indices of tubular function, FeNa, and FeUrea are not diagnostically accurate, prognostically valuable, or clinically useful in septic patients with AKI $[40,41]$. In patients with oliguria, fluid challenge reversed oliguria in only one half of the patients and that neither urinary sodium, FeNa, nor FeUrea was a good predictor of renal response to fluid challenge [42]. Therefore, these parameters must always be interpreted within the clinical context and in conjunction with hemodynamic measurements.

\section{Biomarkers of kidney injury}

The current definition and classification of AKI tell nothing about whether the dysfunction is purely functional or completely structural-these two extremes likely do not exist. Serum creatinine is the defining indicator of AKI in 
Table 3 Biochemical parameters in prerenal and renal AKI

\begin{tabular}{|c|c|c|c|}
\hline Parameters & Prerenal & Renal & Comments \\
\hline $\begin{array}{l}\text { Urine-specific } \\
\text { gravity }\end{array}$ & $>1.020$ & $\begin{array}{l}1.008- \\
1.012\end{array}$ & $\begin{array}{l}\text { In chronic kidney disease and renal AKI, urine-specific gravity is not reliable in the assessment of intravascular } \\
\text { volume depletion due to lack of renal concentrating ability }\end{array}$ \\
\hline $\mathrm{BUN} / \mathrm{Cr}$ & $>20: 1$ & $10: 1$ & $\begin{array}{l}\text { In prerenal state, BUN is absorbed in proximal tubules out of proportion to GFR and serum creatinine, } \\
\text { increasing the BUN/Cr ratio. } \\
\text { Caveats: Steroid therapy and low muscle mass can increase the ratio and decreased protein intake can lower } \\
\text { the ratio. }\end{array}$ \\
\hline Urine sodium & $\begin{array}{l}< \\
20 \mathrm{mEq} /\end{array}$ & $20 \mathrm{mEq} /$ & $>20 \mathrm{mEq} / \mathrm{L}$ in ATN and diuretic therapy \\
\hline FeNa & $<1.0 \%$ & $>2.0 \%$ & $\begin{array}{l}\text { Caveats: Low FeNa is seen in contrast nephropathy, rhabdomyolysis, glomerulonephritis, vasculitis, and acute } \\
\text { tubular necrosis (ATN) in the setting of cirrhosis and congestive heart failure. High FeNa }(>2.0 \%) \text { is seen in AKI } \\
\text { (e.g., ATN) and with diuretic use even in the setting of shock and hypovolemia }\end{array}$ \\
\hline FeUrea & $<35 \%$ & $>50 \%$ & Useful in the setting of diuretic use \\
\hline
\end{tabular}

ATN acute tubular necrosis, FeNa fractional excretion of sodium, FeUrea fractional excretion of urea

KDIGO guideline. But it has been shown, serum creatinine, to be a lagging indicator of AKI development and it is easily influenced by many factors, including sex, muscle mass, and some medications.

The search for early identification of AKI has led to the development of multiple biomarkers of AKI capable of detecting kidney injury at its early stage. A series of molecules have been evaluated over the years, and significant advances have been made in the field. Several biomarkers have been shown to have predictive ability in recognizing kidney damage earlier than creatinine but have not entered mainstream use as yet. It has been proposed to measure these biomarkers as functional (e.g., serum creatinine, serum cystatin C) and damage (e.g., NGAL, neutrophil gelatinaseassociated lipocalin; KIM-1, kidney injury molecule-1; TIMP2, tissue inhibitor of metalloproteinases 2; IGFBP3, insulin-like growth factor-binding protein 3) markers in combination to improve the diagnostic categorization of AKI and permit more guided interventions [43].

Cystatin $\mathrm{C}$ is a small protein produced by nucleated cells and eliminated by GFR. It behaves therefore similar to serum creatinine but is less dependent on muscle mass. In ICU patients, cystatin $\mathrm{C}$ will detect AKI 12 days earlier before the rise of serum creatinine. Its costly measurement limits its routine use.

Molecules such as NGAL and KIM-1 have demonstrated some capacity to detect an injury to the kidney well before the rise of serum creatinine can be observed. Measurement of serum or urine NGAL has been shown to be a good diagnostic test for AKI and prognostic indicator of RRT need and mortality in patients with shock in many studies [44-46] but not all [47]. However, routine use of NGAL in clinical setting is limited due to its increase in both serum and urine which may be related to the presence of a systemic inflammatory state including sepsis and not necessarily the development of AKI [48].

In 2013, the SAPPHIRE study was the first investigation to find and validate the two top urinary biomarkers for the prediction of AKI risk among 340 proteins in a discovery cohort. These biomarkers, urine insulin-like growth factor-binding protein 7 (IGFBP7) and tissue inhibitor of metalloproteinase-2 (TIMP-2), were then validated in $>700$ critically ill adult patients [49]. A simple product of these biomarker levels (TIMP-2 $\times$ IGFBP7), expressed in $(\mathrm{ng} / \mathrm{mL})^{2} / 1000$, launched as a final commercial product, known as NephroCheck. The cutoffs of $>0.3$ and $>2(\mathrm{ng} / \mathrm{mL})^{2} / 1000$ were associated with a progressively increased risk of AKI and major adverse kidney events (death, the need of RRT or persistent renal dysfunction) [49]. NephroCheck of $<0.3(\mathrm{ng} / \mathrm{mL})^{2} / 1000$ had a negative predictive value of $96 \%$ following adjustment for the prevalence of AKI [50-52]. These kidney damage biomarkers are currently under evaluation for routine clinical use.

\section{Urine microscopy}

Examination of urine sediments by microscopy can provide insight into the etiology of renal AKI [53]. Urine sediment in prerenal AKI is generally bland with some hyaline casts and no cellular shedding or crystals. The presence of renal tubular epithelial cell casts (Fig. 1a) and "Muddy" brown granular casts (Fig. 1b) suggests acute tubular injury/necrosis (ATN) as the etiology of AKI. White blood cell casts are generally seen in acute interstitial nephritis or acute pyelonephritis (Fig. 1c). Red cell cast denotes glomerular disease as in glomerulonephritis or small vessel vasculitis (Fig. 1d). Urine sediments can not only help to differentiate prerenal AKI from renal AKI but can also provide insight as to the site of nephron injury.

\section{Management of AKI}

\section{Fluid volume expansion}

If clinical assessment points toward intravascular volume deficit, optimization of the hemodynamic status and correction of any volume deficit should have a salutary 


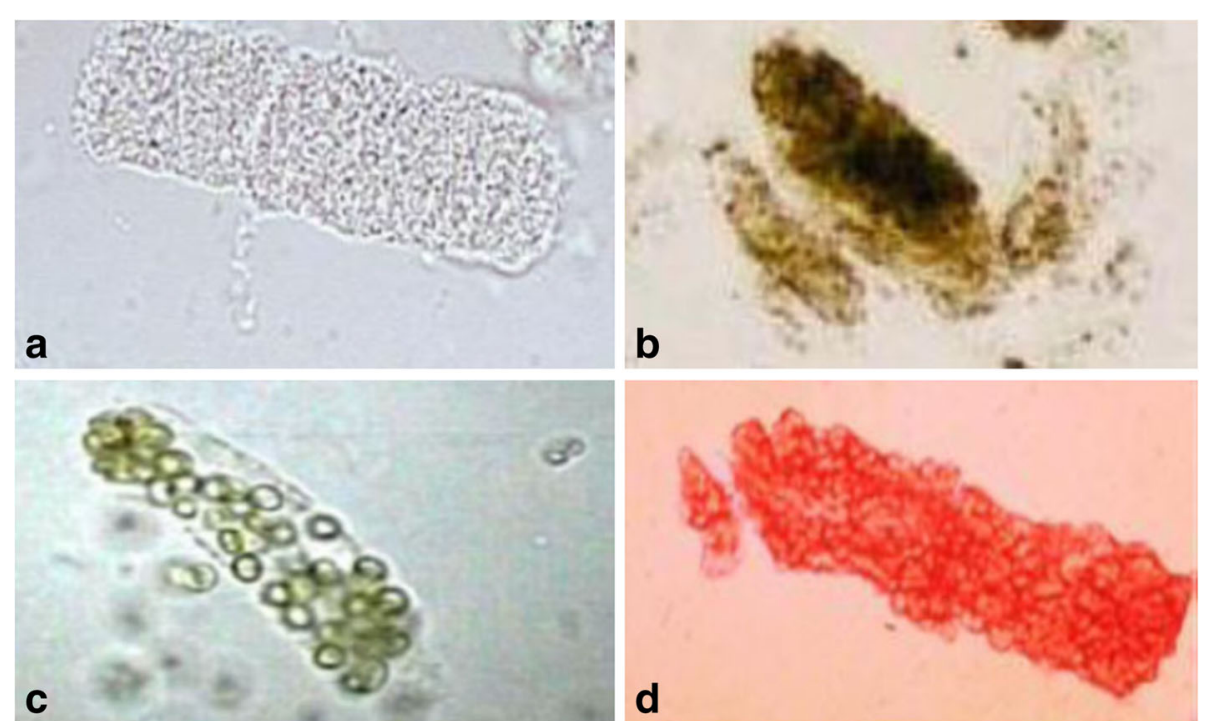

Fig. 1 Urine microscopy for analysis of urine sediments. Renal tubular epithelial cell casts (a) and "Muddy" brown granular casts (b) suggest acute tubular injury/necrosis (ATN) as the etiology of AKI. White blood cell casts are generally seen in acute interstitial nephritis or acute pyelonephritis (c). Red cell cast denotes glomerular disease as in glomerulonephritis or small vessel vasculitis (d)

effect on kidney function and help to minimize further extension of the kidney injury [54]. Fluid resuscitation should be done while monitoring urine output, blood pressure, or CVP dynamic changes as endpoints to avoid excessive fluid administration. In a retrospective analysis of 105 ICU patients, a linear correlation was found between elevated levels of CVP and AKI incidence or its duration [55]. This is due to increased venous congestion and decreased pressure gradient across the glomerulus lowering GFR. Large multicenter studies have shown that a positive fluid balance is an important factor associated with increased 60-day mortality [56-58]. Observational data suggest that buffered crystalloids with low-chloride content may be associated with a decreased risk of AKI $[59,60]$. The plausibility of this notion is that the unphysiologic chloride concentration $(154 \mathrm{mEq} / \mathrm{L})$ in normal saline can cause renal vasoconstriction, decreased glomerular filtration, and metabolic acidosis [61, 62]. However, a recent randomized controlled trial of low-chloride buffered crystalloid solution vs. normal saline showed no difference in the incidence of AKI in a heterogeneous population of patients treated in ICU [63]. As pointed out by the authors of this trial, further studies are needed to assess efficacy of buffered crystalloid solutions in higher-risk populations and to measure clinical outcomes such as mortality.

Colloid solutions such albumin can be used in patients with hypoalbuminemia in the setting of fluid volume deficit, hypotension, and AKI. Albumin infusion is also indicated in patients with liver cirrhosis with AKI in the form of hepatorenal syndrome in conjunction with vasopressors.

\section{Vasopressors}

In septic shock with AKI norepinephrine is the vasopressor of choice with target mean arterial pressure of 65-70 mmHg. However, in patient with chronic hypertension, a higher target mean arterial pressure of 80 $85 \mathrm{mmHg}$ is recommended [64]. The target mean arterial blood pressure of $65-70 \mathrm{mmHg}$ is also applicable in patients with hepatorenal syndrome $[65,66]$. In hepatorenal syndrome, all vasoconstrictors should include cotherapy with albumin.

\section{Diuretics}

Earlier studies have demonstrated improved outcome with aggressive use of loop diuretics in AKI despite an increase in serum creatinine [67-69]. A study demonstrated that a urinary output of at least $100 \mathrm{ml} / \mathrm{h}$ following a test dose of 1.0-1.5 mg furosemide per kilogram body weight predicted lower risk of progression to a higher stage of AKI in oliguric patients [70]. However, in a multi-center randomized controlled trial in adult patients with AKI, low-dose furosemide $(0.4 \mathrm{mg} / \mathrm{kg}$ loading dose followed by a continuous infusion commenced at a dose of $0.05 \mathrm{mg} / \mathrm{kg} / \mathrm{h}$ ) did not reduce the rate of worsening of AKI, improve recovery, or reduce the need for RRT [71]. This seemingly disparate findings are likely related to the differences in pharmacokinetics and pharmacodynamics of furosemide due to the degree of impairment of creatinine clearance in patients with AKI. In this study, measured creatinine clearance was strongly associated with the amount of urinary furosemide excreted and was the only reliable predictor of the urinary output after furosemide [72]. In a recent statement, the 
European Society of Intensive Care Medicine recommended against loop diuretics given solely for the prevention of AKI [64]. However, in patient with AKI and hypervolemia such as in cardiorenal syndrome with decompensated heart failure, loop diuretics should be employed. Diuretics in the setting of AKI have not been shown to cause nephrotoxicity.

\section{Renal replacement therapy}

Currently, the decision to start RRT is based most often on clinical features of volume overload and serum biochemical abnormalities (azotemia, hyperkalemia, severe metabolic acidosis). This overall approach should be based on patient's clinical context and be individualized. Metabolic acidosis associated with AKI can usually be corrected with bicarbonate and should rarely require urgent dialysis if not accompanied by volume overload or uremic syndrome [73].

There have been no systematic studies showing a definitive advantage for any RRT modality-continuous vs. intermittent RRT-on short-term patient or kidney survival [74]. However, the current consensus is considered continuous RRT to be appropriate for patients with AKI with hemodynamic instability, fluid overload, catabolism, or sepsis. Continuous RRT is also indicated in any patient who meets the criteria for intermittent hemodialysis but cannot undergo this procedure because of hemodynamic instability.

The timing of RRT, early vs. late, after AKI has been studied in observational and prospective studies $[75,76]$. Overall, late RRT was associated with a longer duration of RRT and hospital stay and with greater dialysis dependence $[77,78]$. The most recent study on this subject is a randomized controlled trial in 231 critically ill patients with AKI (KDIGO stage 2: with $\geq 2$-fold increase in serum creatinine from baseline or urinary output < $0.5 \mathrm{~mL} / \mathrm{kg} / \mathrm{h}$ for $\geq 12 \mathrm{~h}$ ) and plasma NGAL level higher than $150 \mathrm{ng} / \mathrm{mL}$. Early initiation of RRT within $8 \mathrm{~h}$ of KDIGO stage 2 AKI significantly reduced 90-day mortality $(39.3 \%)$ compared with delayed initiation of RRT (54.7\%; hazard ratio, 0.66 [95\%CI, 0.45 to 0.97 ], $P=.03$ ). In the early RRT group, renal function recovery was faster with shorter ICU stay compared with the delayed RRT group [79]. However, this study had limited generalizability as almost all patients recruited were surgical patients and was a single center trial. It should be noted that the conventional indications for RRT in AKI (volume overload, hyperkalemia, severe metabolic acidosis, or uremic symptoms) in this study were not necessarily part of inclusion criteria. In those studies that classic indications were used to compare early vs. delayed RRT, no significant difference in mortality was found $[80,81]$. More recent studies that included metaanalysis and randomized multicenter trial showed no added benefit of early initiation of RRT for patients with AKI with respect to dialysis dependence, recovery of renal functions, hospital stay, or all-cause mortality [82, 83]. A strategy of delayed initiation of RRT in critically ill patients with severe AKI obviated the need for RRT in almost $50 \%$ of cases [83]. Although there was no mortality difference between early and delayed initiation of RRT groups, the recovery of renal function, as marked by diuresis, was more rapid and catheter-related infections occurred less frequently in the delayed-strategy group than in the early strategy group [83]. In this AKIKI Study Group multicenter trial, the patient had more severe AKI with KDIGO stage 3 reducing the generalizability of the study among different staging.

Evidence from large clinical trials on RRT suggests that the mean duration of treatment is $12-13$ days. In clinical practice, daily assessment of both the intrinsic kidney function and the ongoing appropriateness of RRT are required. The recovery of native kidney function can be assessed during RRT by the serial measurement of serum creatinine as well as attention to urine output. Solute clearance of $25-35 \mathrm{~mL} / \mathrm{min}$ during RRT will result in a stable serum creatinine after $48 \mathrm{~h}$, and further reduction may imply some return of native function. As the renal tubular cells regenerate and re-establish a normal tubular membrane, glomerular filtration will resume and urine output will increase. Increased spontaneous urinary output $>400 \mathrm{~mL} /$ day has been described as a good predictor of successful discontinuation of RRT. Conversely, CKD was a strong negative predictor of successful discontinuation of RRT [84].

\section{Conclusion}

AKI is prevalent in critically ill patients in ICU. The most common etiologies of AKI in these patients are due to fluid volume deficit or kidney hypoperfusion and ATN due to shock, inflammatory state, or nephrotoxic drugs. Early recognition of pathophysiology of AKI by careful review of patient's history and hospital course and intravascular volume assessment complemented by urine biochemical analysis and urine microscopy should guide management strategy in order to reduce further progression of AKI and mortality.

\section{Abbreviations}

ACE: Angiotensin converting enzyme; AKI: Acute kidney injury; ATN: Acute tubular necrosis; CKD: Chronic kidney disease; CVP: Central venous pressure; GFR: Glomerular filtration rate; ICU: Intensive care unit; IGFBP3: Insulin-like growth factor-binding protein 3; KDIGO: Kidney Disease: Improving Global Outcomes; KIM-1: Kidney injury molecule-1; NGAL: Neutrophil gelatinase-associated lipocalin; NSAIDs: Non-steroidal anti-inflammatory drugs; PPV: Positive predictive value; RIFLE criteria: Risk, Injury, Failure, Loss, End Stage; RRT: Renal replacement therapy; TIMP2: Tissue inhibitor of metalloproteinases 2 
Funding

None

\section{Availability of data and materials \\ Not applicable}

Ethics approval and consent to participate

Not applicable

Consent for publication

Not applicable

\section{Competing interests}

The author declares no competing interests.

\section{Publisher's Note}

Springer Nature remains neutral with regard to jurisdictional claims in published maps and institutional affiliations.

Received: 20 March 2017 Accepted: 10 September 2017

Published online: 16 September 2017

\section{References}

1. Kaufman J, Dhakal M, Patel B, Hamburger R. Community-acquired acute renal failure. Am J Kidney Dis. 1991:17:191-8.

2. Mehta RL, Pascual MT, Soroko S, Savage BR, Himmelfarb J, Ikizler TA, et al. Spectrum of acute renal failure in the intensive care unit: the PICARD experience. Kidney Int. 2004;66:1613-21.

3. Uchino S, Kellum JA, Bellomo R, Doig GS, Morimatsu H, Morgera S, et al. Acute renal failure in critically ill patients: a multinational, multicenter study. JAMA. 2005;294:813-8.

4. Brivet FG, Kleinknecht DJ, Loirat P, Landais PJ. Acute renal failure in intensive care units - causes, outcome, and prognostic factors of hospital mortality; a prospective, multicenter study. French Study Group on Acute Renal Failure. Crit Care Med. 1996;24:192-8.

5. Mehta RL, McDonald B, Gabbai FB, Pahl M, Pascual MT, Farkas A, et al. A randomized clinical trial of continuous versus intermittent dialysis for acute renal failure. Kidney Int. 2001;60:1154-63.

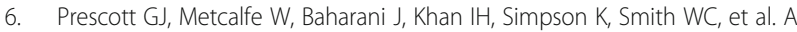
prospective national study of acute renal failure treated with RRT: incidence, aetiology and outcomes. Nephrol Dialysis Transplant. 2007;22:2513-9.

7. Kellum JA, Mehta RL, Angus DC, Palevsky P, Ronco C, Workgroup A. The first international consensus conference on continuous renal replacement therapy. Kidney Int. 2002;62:1855-63.

8. Mehta RL, Kellum JA, Shah SV, Molitoris BA, Ronco C, Warnock DG, et al. Acute Kidney Injury Network: report of an initiative to improve outcomes in acute kidney injury. Crit Care. 2007;11:R31.

9. Khwaja A. KDIGO clinical practice guidelines for acute kidney injury. Nephron Clin Pract. 2012;120:c179-84.

10. Bellomo R, Ronco C, Kellum JA, Mehta RL, Palevsky P, Acute Dialysis Quality Initiative Working Group. Acute renal failure-definition, outcome measures, animal models, fluid therapy and information technology needs: the Second International Consensus Conference of the Acute Dialysis Quality Initiative (ADQI) Group. Crit Care. 2004;8:R204-12.

11. Grootendorst DC, Michels WM, Richardson JD, Jager KJ, Boeschoten EW, Dekker FW, et al. The MDRD formula does not reflect GFR in ESRD patients. Nephrol Dialysis Transplant. 2011;26:1932-7.

12. Pickering JW, Ralib AM, Endre ZH. Combining creatinine and volume kinetics identifies missed cases of acute kidney injury following cardiac arrest. Crit Care. 2013;17:R7.

13. Prowle JR, Kolic I, Purdell-Lewis J, Taylor R, Pearse RM, Kirwan CJ. Serum creatinine changes associated with critical illness and detection of persistent renal dysfunction after AKI. Clin J Am Soc Nephrol. 2014;9:1015-23.

14. Bellomo R, Kellum JA, Ronco C. Acute kidney injury. Lancet. 2012;380:756-66.

15. Amdur RL, Chawla LS, Amodeo S, Kimmel PL, Palant CE. Outcomes following diagnosis of acute renal failure in U.S. veterans: focus on acute tubular necrosis. Kidney Int. 2009;76:1089-97.

16. Coca SG, Yusuf B, Shlipak MG, Garg AX, Parikh CR. Long-term risk of mortality and other adverse outcomes after acute kidney injury: a systematic review and meta-analysis. Am J Kidney Dis. 2009;53:961-73.
17. Wald R, Quinn RR, Luo J, Li P, Scales DC, Mamdani MM, et al. Chronic dialysis and death among survivors of acute kidney injury requiring dialysis. JAMA. 2009;302:1179-85.

18. Chawla LS, Abell L, Mazhari R, Egan M, Kadambi N, Burke HB, et al. Identifying critically ill patients at high risk for developing acute renal failure: a pilot study. Kidney Int. 2005;68:2274-80.

19. Carlstrom M, Wilcox CS, Arendshorst WJ. Renal autoregulation in health and disease. Physiol Rev. 2015;95:405-511.

20. Green T, Gonzalez AA, Mitchell KD, Navar LG. The complex interplay between cyclooxygenase-2 and angiotensin II in regulating kidney function. Curr Opin Nephrol Hypertens. 2012;21:7-14.

21. Harris RC. Physiologic and pathophysiologic roles of cyclooxygenase-2 in the kidney. Trans Am Clin Climatol Assoc. 2013;124:139-51.

22. Kleinstreuer N, David T, Plank MJ, Endre Z. Dynamic myogenic autoregulation in the rat kidney: a whole-organ model. Am J Physiol Renal Physiol. 2008;294:F1453-64.

23. Fournier JP, Lapeyre-Mestre M, Sommet A, Dupouy J, Poutrain JC, Montastruc JL. Laboratory monitoring of patients treated with antihypertensive drugs and newly exposed to non steroidal antiinflammatory drugs: a cohort study. PLoS One. 2012;7:e34187.

24. Lapi F, Azoulay L, Yin H, Nessim SJ, Suissa S. Concurrent use of diuretics, angiotensin converting enzyme inhibitors, and angiotensin receptor blockers with non-steroidal anti-inflammatory drugs and risk of acute kidney injury: nested case-control study. BMJ. 2013;346:e8525.

25. Ravikant T, Lucas CE. Renal blood flow distribution in septic hyperdynamic pigs. J Surg Res. 1977;22:294-8.

26. Di Giantomasso D, Morimatsu H, May CN, Bellomo R. Intrarenal blood flow distribution in hyperdynamic septic shock: effect of norepinephrine. Crit Care Med. 2003;31:2509-13.

27. Brenner M, Schaer GL, Mallory DL, Suffredini AF, Parrillo JE. Detection of renal blood flow abnormalities in septic and critically ill patients using a newly designed indwelling thermodilution renal vein catheter. Chest. 1990;98:170-9.

28. Prowle JR, Ishikawa K, May CN, Bellomo R. Renal blood flow during acute renal failure in man. Blood Purif. 2009;28:216-25

29. Hotchkiss RS, Swanson PE, Freeman BD, Tinsley KW, Cobb JP, Matuschak GM, et al. Apoptotic cell death in patients with sepsis, shock, and multiple organ dysfunction. Crit Care Med. 1999;27:1230-51.

30. Takasu O, Gaut JP, Watanabe E, To K, Fagley RE, Sato B, et al. Mechanisms of cardiac and renal dysfunction in patients dying of sepsis. Am J Respir Crit Care Med. 2013;187:509-17.

31. Wang Z, Holthoff JH, Seely KA, Pathak E, Spencer HJ 3rd, Gokden N, et al. Development of oxidative stress in the peritubular capillary microenvironment mediates sepsis-induced renal microcirculatory failure and acute kidney injury. Am J Pathol. 2012;180:505-16.

32. Murugan R, Karajala-Subramanyam V, Lee M, Yende S, Kong L, Carter M, et al. Acute kidney injury in non-severe pneumonia is associated with an increased immune response and lower survival. Kidney Int. 2010;77:527-35.

33. Huen SC, Cantley LG. Macrophage-mediated injury and repair after ischemic kidney injury. Pediatr Nephrol. 2015;30:199-209.

34. Mehta RL, McDonald B, Gabbai F, Pahl M, Farkas A, Pascual MT, et al. Nephrology consultation in acute renal failure: does timing matter? Am J Med. 2002;113:456-61.

35. Palmer BF. Renal dysfunction complicating the treatment of hypertension. New Engl J Med. 2002;347:1256-61.

36. Feissel M, Michard F, Faller JP, Teboul $\mathrm{J}$. The respiratory variation in inferior vena cava diameter as a guide to fluid therapy. Intensive Care Med. 2004;30:1834-7.

37. Mohsenin V. Assessment of preload and fluid responsiveness in intensive care unit. How good are we? J Crit Care. 2015;30:567-73.

38. Magder S, Georgiadis G, Cheong T. Respiratory variations in right atrial pressure predict the response to fluid challenge. J Crit Care. 1992;7:76-85.

39. Michard F, Boussat S, Chemla D, Anguel N, Mercat A, Lecarpentier $Y$, et al. Relation between respiratory changes in arterial pulse pressure and fluid responsiveness in septic patients with acute circulatory failure. Am J Respir Crit Care Med. 2000;162:134-8.

40. Bagshaw SM, Langenberg C, Bellomo R. Urinary biochemistry and microscopy in septic acute renal failure: a systematic review. Am J Kidney Dis. 2006;48:695-705.

41. Bagshaw SM, Langenberg C, Wan L, May CN, Bellomo R. A systematic review of urinary findings in experimental septic acute renal failure. Crit Care Med. 2007;35:1592-8. 
42. Legrand M, Le Cam B, Perbet S, Roger C, Darmon M, Guerci P, et al. Urine sodium concentration to predict fluid responsiveness in oliguric ICU patients: a prospective multicenter observational study. Crit Care. 2016;20:165.

43. Murray PT, Mehta RL, Shaw A, Ronco C, Endre Z, Kellum JA, et al. Potential use of biomarkers in acute kidney injury: report and summary of recommendations from the 10th Acute Dialysis Quality Initiative consensus conference. Kidney Int. 2014;85:513-21.

44. Haase M, Bellomo R, Devarajan P, Schlattmann P, Haase-Fielitz A, Group NMal. Accuracy of neutrophil gelatinase-associated lipocalin (NGAL) in diagnosis and prognosis in acute kidney injury: a systematic review and meta-analysis. Am J Kidney Dis. 2009;54:1012-24.

45. Wang M, Zhang Q, Zhao X, Dong G, Li C. Diagnostic and prognostic value of neutrophil gelatinase-associated lipocalin, matrix metalloproteinase-9, and tissue inhibitor of matrix metalloproteinases-1 for sepsis in the emergency department: an observational study. Crit Care. 2014;18:634.

46. Ralib AM, Pickering JW, Shaw GM, Than MP, George PM, Endre ZH. The clinical utility window for acute kidney injury biomarkers in the critically ill. Crit Care. 2014;18:601.

47. Hjortrup PB, Haase N, Treschow F, Moller MH, Perner A. Predictive value of NGAL for use of renal replacement therapy in patients with severe sepsis. Acta Anaesthesiol Scand. 2015;59:25-34.

48. Lentini P, de Cal M, Clementi A, D'Angelo A, Ronco C. Sepsis and AKI in ICU patients: the role of plasma biomarkers. Crit Care Res Pract. 2012;2012:856401

49. Kashani K, Al-Khafaji A, Ardiles T, Artigas A, Bagshaw SM, Bell M, et al. Discovery and validation of cell cycle arrest biomarkers in human acute kidney injury. Crit Care. 2013;17:R25.

50. Bihorac A, Chawla LS, Shaw AD, Al-Khafaji A, Davison DL, Demuth GE, et al. Validation of cell-cycle arrest biomarkers for acute kidney injury using clinical adjudication. Am J Respir Crit Care Med. 2014;189:932-9.

51. Koyner JL, Shaw AD, Chawla LS, Hoste EA, Bihorac A, Kashani K, et al. Tissue inhibitor metalloproteinase-2 (TIMP-2)|GF-binding protein-7 (IGFBP7) levels are associated with adverse long-term outcomes in patients with AKI. J Am Soc Nephrol. 2015;26:1747-54.

52. Vijayan A, Faubel S, Askenazi DJ, Cerda J, Fissell WH, Heung M, et al. Clinical use of the urine biomarker [TIMP-2] x [IGFBP7] for acute kidney injury risk assessment. Am J Kidney Dis. 2016;68:19-28.

53. Perazella MA. The urine sediment as a biomarker of kidney disease. Am J Kidney Dis. 2015;66:748-55.

54. Joannidis M. Drug-induced renal failure in the ICU. Int J Artificial Organs. 2004; $27: 1034-42$.

55. Legrand M, Dupuis C, Simon C, Gayat E, Mateo J, Lukaszewicz AC, et al. Association between systemic hemodynamics and septic acute kidney injury in critically ill patients: a retrospective observational study. Crit Care. 2013;17:R278.

56. Bouchard J, Soroko SB, Chertow GM, Himmelfarb J, Ikizler TA, Paganini EP, et al. Fluid accumulation, survival and recovery of kidney function in critically ill patients with acute kidney injury. Kidney Int. 2009;76:422-7.

57. Prowle JR, Bellomo R. Continuous renal replacement therapy: recent advances and future research. Nature Rev Nephrol. 2010;6:521-9.

58. Prowle JR, Echeverri JE, Ligabo EV, Ronco C, Bellomo R. Fluid balance and acute kidney injury. Nature Rev Nephrol. 2010;6:107-15.

59. Yunos NM, Bellomo R, Bailey M. Chloride-restrictive fluid administration and incidence of acute kidney injury. JAMA. 2013;309:543-4.

60. Shaw AD, Bagshaw SM, Goldstein SL, Scherer LA, Duan M, Schermer CR, et al. Major complications, mortality, and resource utilization after open abdominal surgery: 0.9\% saline compared to plasma-lyte. Ann Surg. 2012;255:821-9.

61. Bullivant EM, Wilcox CS, Welch WJ. Intrarenal vasoconstriction during hyperchloremia: role of thromboxane. Am J Phys. 1989;256:F152-7.

62. Yunos NM, Kim IB, Bellomo R, Bailey M, Ho L, Story D, et al. The biochemical effects of restricting chloride-rich fluids in intensive care. Crit Care Med. 2011;39:2419-24.

63. Young P, Bailey M, Beasley R, Henderson S, Mackle D, McArthur C, et al. Effect of a buffered crystalloid solution vs saline on acute kidney injury among patients in the intensive care unit: the SPLIT randomized clinical trial. JAMA. 2015;314:1701-10

64. Joannidis M, Druml W, Forni LG, Groeneveld ABJ, Honore PM, Hoste E, et al. Prevention of acute kidney injury and protection of renal function in the intensive care unit: update 2017 : expert opinion of the working group on prevention, AKI section, European Society of Intensive Care Medicine. Intensive Care Med. 2017;43:730-49.
65. Singh V, Ghosh S, Singh B, Kumar P, Sharma N, Bhalla A, et al. Noradrenaline vs. terlipressin in the treatment of hepatorenal syndrome: a randomized study. J Hepatol. 2012;56:1293-8.

66. Adebayo D, Morabito V, Davenport A, Jalan R. Renal dysfunction in cirrhosis is not just a vasomotor nephropathy. Kidney Int. 2015;87:509-15.

67. Grams ME, Estrella MM, Coresh J, Brower RG, Liu KD, National Heart L, et al. Fluid balance, diuretic use, and mortality in acute kidney injury. Clin J Am Soc Nephrol. 2011;6:966-73.

68. Testani JM, Chen J, McCauley BD, Kimmel SE, Shannon RP. Potential effects of aggressive decongestion during the treatment of decompensated heart failure on renal function and survival. Circulation. 2010;122:265-72.

69. Testani JM, Coca SG, McCauley BD, Shannon RP, Kimmel SE. Impact of changes in blood pressure during the treatment of acute decompensated heart failure on renal and clinical outcomes. Eur J Heart Fail. 2011;13:877-84.

70. Chawla LS, Davison DL, Brasha-Mitchell E, Koyner JL, Arthur JM, Shaw AD, et al. Development and standardization of a furosemide stress test to predict the severity of acute kidney injury. Crit Care. 2013;17:R207.

71. Bagshaw SM, Gibney RTN, Kruger P, Hassan I, McAlister FA, Bellomo R. The effect of low-dose furosemide in critically ill patients with early acute kidney injury: a pilot randomized blinded controlled trial (the SPARK study). J Crit Care. 2017:42:138-46.

72. Silbert BI, Ho KM, Lipman J, Roberts JA, Corcoran TB, Morgan DJ, et al. Determinants of urinary output response to IV furosemide in acute kidney injury: a pharmacokinetic/pharmacodynamic study. Crit Care Med. 2016:44:e923-9.

73. Gauthier PM, Szerlip HM. Metabolic acidosis in the intensive care unit. Crit Care Clin. 2002;18:289-308. vi

74. Nash DM, Przech S, Wald R, O'Reilly D. Systematic review and meta-analysis of renal replacement therapy modalities for acute kidney injury in the intensive care unit. J Crit Care. 2017;41:138-44.

75. Leite TT, Macedo E, Pereira SM, Bandeira SR, Pontes PH, Garcia AS, et al. Timing of renal replacement therapy initiation by AKIN classification system. Crit Care. 2013;17:R62.

76. Shiao CC, Wu VC, Li WY, Lin YF, Hu FC, Young GH, et al. Late initiation of renal replacement therapy is associated with worse outcomes in acute kidney injury after major abdominal surgery. Crit Care. 2009;13:R171.

77. Bagshaw SM, Uchino S, Bellomo R, Morimatsu H, Morgera S, Schetz M, et al. Timing of renal replacement therapy and clinical outcomes in critically ill patients with severe acute kidney injury. J Crit Care. 2009;24:129-40.

78. Karvellas CJ, Farhat MR, Sajjad I, Mogensen SS, Leung AA, Wald R, et al. A comparison of early versus late initiation of renal replacement therapy in critically ill patients with acute kidney injury: a systematic review and metaanalysis. Crit Care. 2011;15:R72

79. Zarbock A, Kellum JA, Schmidt C, Van Aken H, Wempe C, Pavenstadt H, et al. Effect of early vs delayed initiation of renal replacement therapy on mortality in critically ill patients with acute kidney injury: the ELAIN randomized clinical trial. JAMA. 2016;315:2190-9.

80. Jamale TE, Hase NK, Kulkarni M, Pradeep KJ, Keskar V, Jawale S, et al. Earlier-start versus usual-start dialysis in patients with community-acquired acute kidney injury: a randomized controlled trial. Am J Kidney Dis. 2013;62:1116-21.

81. Wald R, Adhikari NK, Smith OM, Weir MA, Pope K, Cohen A, et al. Comparison of standard and accelerated initiation of renal replacement therapy in acute kidney injury. Kidney Int. 2015;88:897-904.

82. Bhatt GC, Das RR. Early versus late initiation of renal replacement therapy in patients with acute kidney injury-a systematic review \& meta-analysis of randomized controlled trials. BMC Nephrol. 2017;18:78

83. Gaudry S, Hajage D, Schortgen F, Martin-Lefevre L, Pons B, Boulet E, et al. Initiation strategies for renal-replacement therapy in the intensive care unit. New Engl J Med. 2016;375:122-33.

84. Uchino S, Bellomo R, Morimatsu H, Morgera S, Schetz M, Tan I, et al. Discontinuation of continuous renal replacement therapy: a post hoc analysis of a prospective multicenter observational study. Crit Care Med. 2009;37:2576-82. 